TITLE:

\title{
Anisotropic Structure of Polyethylene Fiber and Its Related Properties(Dissertation_全文)
}

\author{
$\operatorname{AUTHOR}(\mathrm{S}):$
}

Ohde, Yoshihito

\section{CITATION:}

Ohde, Yoshihito. Anisotropic Structure of Polyethylene Fiber and Its Related Properties. 京 都大学, 1974, 理学博士

ISSUE DATE:

1974-09-24

URL:

https://doi.org/10.14989/doctor.k1522

RIGHT: 


$$
\text { 学位中清諞文 }
$$

大出義仁 


\title{
1
}

主論文

Anisotropic Structure of Polyethylene Fiber and Its Related Properties Yoshihito Ohde: Japan. J. appl. Phys. vol.13, No.7, in press.

\author{
参考論文 \\ Deformation of Sedimented Mats of Polyethylene Single Crystals \\ Yoshihito Ohde, Hideki Miyaji, Kenjiro Asai: Japan. J. appl. Phys. \\ vol.10 (1971) 171.
}

\section{参考論文}

Dielectric Properties of Mixture of Lauryl-Laurate and Hexacosane

Hideki Miyaji, Yoshihito Ohde and Kenjiro Asai: J. Phyo. Soc. Japan' vol.32 (1972) 1182. 
Anisotropic Structure of Polyethylene Fiber and Its Related Properties Yoshihito $\mathrm{OHDE}^{*}$

Department of Physics, Faculty of Science, Kyoto University, Kyoto

( Recieved November 13,1973)

* Present Adress : Department of Engineering Science, Nagoya Institute of Technology, Shouwa-ku, Nagoya 464

\section{Synopsis}

Direct observation of internal structure of a bulky polyethylene fiber was made with an electron microscope using selective etching technique by fuming nitric acid. Striations with a period of 230 . making an angle of $45 \mathrm{deg}$. with the fiber axis, and wavy striations with a period of $320 \AA$ perpendicular to the fiber axis, are observed on different fractured surfaces perpendicular to each other. Fibrils of $5000 \AA$ in width are also seen. These values are consistent with a model of double-textured fiber studied by x-ray scattering methods. Amorphous tie molecules between lamellae are oriented perpendicularly to the fiber axis, and parallel to the plane of fiber strip. Tie molecules give the anisotropic structure and the broad range of melting of the fibers. 


\section{§. Introduction}

Polymer chains are usially oriented to the direction of the resultant maximum strain in the severely drawn sample. When the oriented crystalline polymers are annealed, they give meridional or off-meridional reflections ( so-called two-point or four-point pattern ) in x-ray small angle scattering ( XSAS ). I) The mechanism of fiber formation by drawing was proposed by Kobayashi ,2) and by Peterlin. 3) Developement of chain orientation in sedimented mat of polyethylene ( $\mathrm{PE}$ ) single crystals was studied through structural changes by hot press in our previous work. ${ }^{4}$ Morphological investigation of the final fiber texture in severely drawn $\mathrm{PE}$ will help us to understand the mechanism of chain orientation more clearly.

Various models of fiber texture have been proposed by x-ray scattering and electron microscope (EM) studies. 3,5 ) on the structure corresponding to the four-point XSAS, morphological investigations having been reported until now were made chiefly by XSAS method. ${ }^{6 \sim 11)}$ The reliability of the models could be increased by direct EM observation of internal structure of fibers with double texture, but no EM observation has been reported yet. Though Gezovichi et al. succeeded in EM observation of a double texture of as-rolled polyoxymethylene ${ }^{12)}$ and polyethyleneoxide, ${ }^{13)}$ the resultant strain of their specimens appears to be too small to consider the texture to be a model of fiber with double texture. We investigated the internal structure of bulky linear-PE fiber with double texture by direct EM observation of fractured surfaces. The PE fibers were prepared in the same way as used 
by Seto et al. $7 \sim 9$ ), and the anisotropic structure was confirmed by XSAS method. Specimens for the EM observation were made by use of the selective etching technique by fuming nitric acid (FNA) developed by Palmer et al. ${ }^{14)}$, Hay et al. ${ }^{15)}$ and Peteriin et al. ${ }^{16)}$. In the course of the morphological studies, tie molecules were found to play an important role in the anisotropic nature of fiber strips. Hence we investigated and discussed qualitative effects of tie molecules on appearance of the anisotropic structure, and on melting behaviour of the fiber strips.

\section{\}2. Experimental}

Unfractionated linear-PE (Sholex-6009) was molded into $1 \mathrm{~mm}$ thick sheets. They were once melted and then quenched in ice water. Strips about $10 \mathrm{~mm}$ wide were cut out of the sheets and were drawn at room temps. through the stage of necking. Dimensional changes after the neck-drawing were about 8 times in length, $1 / 5 \sim 1 / 6$ time in thickness, and $4 / 5 \sim 5 / 6$ times in width. The neck= drawn parts of strips were then annealed at a temperature between $122 \sim 128^{\circ} \mathrm{C}$ for half a day under zero stress. The sample preparation so far was almost the same as Seto et al. did? 9 )

In the following, the specimens are represented as nfiber strips" or simply "strips". The axes of coordination in the. strip are given in Fig. 1 , where the draw axis and the normal of the plane of fiber are chosen as the $z$ - and $y$-axes respectively.

Two kinds of fractured surfaces of the strips, parallel to the $y-z$ and $x-z$ planes, were prepared at liquid nitrogen temp. to observe the anisotropic stmucture expected from the reports by Seto et $a .^{7^{\sim}}$ ?) Since the $y-z$ fractured surfaces were observed 
to be covered over with microfibrils introduced by the fracture, they were etched by FNA at $80^{\circ} \mathrm{C}$; the density of the nitric acid is $1.50 \mathrm{~g} \cdot \mathrm{cm}^{-3}$. Other strips were treated by FNA at $80^{\circ} \mathrm{C}$ for $1 / 2 \sim 8 \mathrm{~h}$ in advance, and then fractured parallel to the $\mathrm{y-z}$ plane.

These fractured surfaces were shadowed with Pt-C along the z-axis and stripped with polyacrylicacid. The replicas were backed with carbon and the polyacrylicacid supporter was removed in water. Because heavily treated strips were too fragile to apply the above mentioned replication technique, some other strips were Pt-C shadowed, immediately backed with carbon, and removed by exposure to vapour of boiling xylene.

The magnification of the EM ( HU-11 , Hitachi Ltd.) was corrected by $1 / 576$ and $1 / 2000$ mm grating replicas previously to the present experiment. $\mathrm{X}$-ray wide and small angle scattering patterns were taken simultaneously with a point collimated camera, with Ni-filtered $\mathrm{Cu}-\mathrm{K}_{\alpha}$ radiation, at room tempS..

The experimental procedures to investigate effects of tie molecules on the anisotropic structure, and on melting behaviour of the strips will be given in $\S 4$.

\section{Texture of Fractured Surfaces}

The $x$-ray scattering patterns in Fig. 2 were taken with incident beams along the x-axis on the right:one-third portion of the $y-z$ plane of a fiber strip, which was so fixed that the developing direction of the neck during the cold drawing was 
directed upwards along the patterns. The central one-third part fixed in the same orientation gives four-point reflections with equal intensity in XSAS. ( See, for example , Fig. 8a ) The remaining. left part gives the mirror images of the patterns in Fig. 2 with respect to the $x-z$ plane. The XSAS with beams along the $y$-axis gives no trace of off-meridional reflections but meridional two-point reflections. These show that our strips have the same type of double texture and of anisotropic structure as was reported by Seto et al.. 7 9) Further they display a biased distribution of the double texture in the strip.

Seto's model viewed along the $\mathrm{x}$-axis is schematically shown in Fig. 3 together with structural parameters. The twin-like arrangement of adjacent fibrils corresponds to the four-point XSAS. The texture is assumed to develope along the z-axis to explain the meridional two-point pattern with $x$-rays along the y-axis.

From such scattering patterns of strips annealed at $126^{\circ} \mathrm{C}$ as given in Figs. 2 and $8 \mathrm{a}$, the thickness of layers composed of crystalline and amorphous parts , D, is determined as $220 \sim 240 \AA$, and the tilting' angles of the lamellar normal $\theta$ and of chains $\varphi$ reffering to the z-axis are about $45 \mathrm{deg}$. and $5 \mathrm{deg}$. respectively. The long period $L$ is calculated to be about $310 \sim 340 \AA$ by the relation, $\mathrm{L}=\mathrm{D} / \cos \theta$, which is deduced from the model. As to the width of fibrils, W, we assume a lower limit of $W$ to be $350 \AA$ as a criterion for the EM observation, which is calculated from the lower limit of the coherent length for XSAS reflections estimated by Seto et al..8) 
To check the FNA treatment effects on the texture, wide angle $x$-ray pattern of non-treated strips was compared with that of the strip treated at $80^{\circ} \mathrm{C}$ for $40 \mathrm{~h}$. It is seen that, by the treatment, a disorientatj on of chains is caused a little, and amorphous halo in Fig. 4a disappears in Fig. 4b. Since the halo in Fig. 4a is stronger in meridional directions than in the equatorial direction, chains in the amorphous regions are partly oriented perpendicularly to the z-axis. The treatment gradually decreases the intensity of XSAS peaks, and increases the intensity of diffuse scattering near the direct spot. (Fig. 4c) The former is considered to be caused by the increase in electron density. in the amorphous parts due to 1 oxidation, and the latter is ascribed to voids formed by the treatment. The XSAS pattern Fig. $4 c$ is given by the strip treated for $8 \mathrm{~h}$ at $80^{\circ} \mathrm{C}$, and is obtained by 10 times as long exposure to $\mathrm{x}$-rays in the evacuated camera as one given in Fig. 2. The $D$ and $\theta$ remain constant within experimental errors by the treatment for up to $8 \mathrm{~h}$ at least.

In the following the word "fractured" will be abbreviated for brevity. The $\mathrm{y}-\mathrm{z}$ surfaces of non-treated strips are more rough than the $x-z$ surfaces of non-treated strips by the EM observations. From Fig. 5a, structure elements of $5000 \AA$ in width (we call them "fibrils" henceforth) are extending along the z-axis, though they are covered over with microfibrils muning to various directions. Some fibrils were found to protrude from the shadowed film, since 
they were fluttering due to the electron bombardment during EM observation. We cannot see any other characteristic structure in it. In marked contrast to the $y-z$ surfaces, we can see, on the $x-z$ our-: faces, striations with periods of $320 \pm 30 \AA$, which are rather wavy and perpendicular to the z-axis.

Though the $y-z$ surfaces of etched strips are still covered with microfibrils, their $x-z$ surfaces give a clear lamellar structure (Fig. 6) ; lamellae, stacked in layers along the z-axis, exhibit their accidental branching and various waviness.

FNA treatment previous to the fracture were found to reduce the microfibrils appreciably, and periodic striations are observed on the $\mathrm{y}-\mathrm{z}$ surfaces after the treatment for $8 \mathrm{~h}$ at $80^{\circ} \mathrm{C}$. (Fig. 7 ) Since the disappearance of microfibrils is considered to be due to scissions of tie molecules which tightly cnnect contiguous stacks of crystalline layers, tie molecules will not be easily torn up but bring out microfibrils on the fracture, especially on the fracture parallel to the $y-z$ plane - Hence the different roughness of the $x-z$ and $y-z$ surfaces indicates the preferential orientation of tie molecules parallel to the x-axis. This type of orientation has already been suggested by Seto et al.. 7,9 )

From Fig. 7 , the normal of the striations with periods of $230 \pm 30 \AA$ makes an angle of $45 \mathrm{deg}$. with the z-axis. The fibrilar structure in Fig. $5 \mathrm{a}$ is not observed, and a single region with striations inclining in the same direction spreads in an average width of a few ten microns. Of course, this single region might be composed of some fibrils, and the width of fibrils will be more than $5000 \AA$ at least. This satisfies the criterion discribed above. 
Moreover, Seto et al. assumed that adjacent fibrils with rather small width should shift along the z-axis each other to avoid the creation of excess voids due to misfit between them. Our obserw vation means that fibrils are so wide that the importance of the arrangement of fibrils is reduced.

The biased distribution of the double texture seen in Fig. 2 seems to develope on a more macroscopic scale than the width of each fibril. It should be pointed out that the symmetry of the texture is consistent with that of the plastic strain in an as-drawn strip. We can observe the macroscopic local strain by drawing parallel marker= lines perpendicular to the z-axis in advance. After the neck-draw central portions are seen to be drawn more severely than both sides by the distortion of the lines. Such strain pattern is very similar to that of flat metal bar test piece. Hence, in spite of the microscopic texture of the initial strip, the plastic strain is a conspicuous feature of a flat bar test piece. This can explain the symmetry of the texture seen in Fig. 2 , because the symmetry will not be lost before the perfect melting. The inhomogeneity of the initial strip, i.e., spherulitic texture, tends to produce local variations in the plastic strain, which determint the inclining direction of lamellae in each fibril.

It is safely concluded that the results obtained by EM observations agree with those determined by $x$-ray scattering methods, qualitatively in the anisotropic nature and quantitatively in the structural parameters. 


\section{\$ 4. Tie Molecules in Fiber Strips}

Tie molecules have been considered to play some roles on the anisotropic structure, 7,9$)$ and superheating of $\mathrm{PE}$ fibers. 17 19) It is almost confirmed that the FNA treatment cuts tie molecules and weakens the tight connection between lamellae and between fibrils. Hence, effects of the treatment, in other words, effects of decrease in tie molecules on the fiber texture were studied through structural change of the strips by re-annealing. Effects on melting behaviour were also examined with DSC ( Rigaku-thermoflex , Rigakudenki Ltd. )

\subsection{Effects of tie molecules on the anisotropic structure} Strips annealed at $122{ }^{\circ} \mathrm{C}$ were treated for various durations including zero hour, and thereafter re-annealed just below their respective melting points. Their melting points are indicated by $\mathrm{T}_{3}$ in Tables II and III in $\$ 4.2$. Corresponding structural changes studied b. XSAS are given in Fig. 8 and in Table I .

The double texture in non-treated strip is maintained up to at 132.5 ${ }^{\circ} \mathrm{C}$ ( Fig. 8a ) and complete disorientation of lamellae is observed at $133^{\circ} \mathrm{C}$. Re-annealing at $132.8^{\circ} \mathrm{C}$ causes partial disorientation of lamellae, but some of them still hold their initial orientation. (Fig. 8b) On the contrary, the textures of strips once treated for longer than $1 \mathrm{~h}$ are changed by the re-annealing. (Figs. $8 c \sim 8 f$ ) It is notable that such changes will not be caused by stored energy which was accumulated in the amorphous in the course of the previous drawing, ${ }^{10)}$ since the texture in non= treated strip does show considerable stability.

The structural change can be explained as follows. Seto et al. 
suggested that the volume effect discussed by Flory. ${ }^{20)}$ could account for chain tilting in oriented semi-crystalline polymers. Following Flory's discussion, we can deduce a modified equation,

$$
\mathrm{N}_{\mathrm{a}} / \mathrm{N}_{\mathrm{c}}=\mathrm{A}_{\mathrm{c}} /\left(2 \cdot \mathrm{A}_{\mathrm{a}} \cdot \cos \alpha\right)
$$

- where $A_{C}$ and $A_{a}$ are the areas of chain cross-section in crystalline and amorphous regions respectively, and the angle $\alpha$ is the tilting angle of chains mentioned above. Number of crystalline chains crossing unit area of crystal-amorphous interface is represented by $\mathrm{N}_{c}$, and the number $\mathrm{N}_{a}$ is that of chains crossing unit area of a plane placed in the amorphous region apart from the interface by a certain distance. Directions of chains crossing the plane are assumed to be completely random. This condition is not satisfied in the present strips, but here we neglect it. The ratio $\mathrm{N}_{a} / \mathrm{N}_{c}$ is considered to be an upper limit of number fraction of tie molecules, which leave from the interface and cross the plane at least.

Scissions of tie molecules reduce the ratio $\mathrm{N}_{\mathrm{a}} / \mathrm{N}_{\mathrm{c}}$, which leads to the decrease in the angle $\alpha$ following to eq.(1). Thus we can estimate the ratio $\mathrm{N}_{a} / \mathrm{N}_{c}$ from the observed angles $\theta$ and $\varphi$. The last column in Table $I$ is the caluculated values of the ratio, where we assume the ratio of $A_{c}$ to $A_{a}$ equal to unity for simplicity. We obtain a rate of scission of tie molecules to be $9 \%$ per $\mathrm{h}$, which is consistent with the fact that it takes $8 \mathrm{~h}$ to observe the $y-z$ fractured surfaces free from the microfibrils. 


\subsection{Tie molecules and melting behaviour of fiber strips}

Typical thermograms are given in Fig. 9 together wi.th characteristic temperatures, $\mathrm{T}_{1} \sim \mathrm{T}_{4} \cdot$ The $\mathrm{T}_{1}, \mathrm{~T}_{3}$ and $\mathrm{T}_{4}$ are the initiation-, peak- and termination-temps, of the melting respectively. The $\mathrm{T}_{2}$ is the temperature at which the tangential of the melting curve crosses the base line of the thermogram at an angle of $45 \mathrm{deg}$. in the case of a chart speed of $8 \mathrm{~mm}$ per min as shown in Fig. 9 . The $\mathrm{T}_{3}$ is regarded as the melting point of the fiber strip. The effect of heating rate and that of duration of the FNA treatment are studied separately. The former is summarized in Table II, and the latter is in Table III.

Non-treated strip shows appreciable rise in $\mathrm{T}_{4}$; ith a fast heating rate of $20^{\circ} \mathrm{C}$ per min as seen in Table II . The melting point $\mathrm{T}_{3}$ increases a little, but not so appreciable as $\mathrm{T}_{4}$. The high-temp. tails of melting curves are decreased considerably by the FNA treatment.

The effect of treatment duration is very interesting. The treatment of only $1 / 2 \mathrm{~h}$ lowers $\mathrm{T}_{4}$ by $4.5{ }^{\circ} \mathrm{C}$, and further lowering of $\mathrm{T}_{4}$ is only $2^{\circ} \mathrm{C}$ by the treatment for $5 \mathrm{~h}$. ( Table III) Since the treatment for $8 \mathrm{~h}$ enables us to observe the internal structure free from the microfibrils, it is reasonable to assume that scissions of almost all tie molecules need the treatment for $8 \mathrm{~h}$ at least. Further we can assume a constant scission speed from the discussion in $\S .4 .1$. The observation leads to the idea that rather small fraction of tie molecules should owes to the high-temp. tails of melting curves, since a fraction of $93 \%$ or more of tie molecules still survives after the treatment for $1 / 2 \mathrm{~h}$. 
Similar ideas to explain the superhedting of stirred crystals of PE were given by Kawai et al. , 17) Keller et al. ${ }^{18)}$ and Zachmann. ${ }^{19)}$ Zachmann ${ }^{19)}$ studied theoretically the entropy of semi-crystalline polymer, and broad melting in such system could be ascribed to the decrease in the entropy of melting due to two factors; the one was that both ends of non-crystalline parts of chains were fixed, and the other was that volume available to those parts of chains were limited by sorrounding crystallites. Such considerations can be applicable to the present strips.

By a short treatment, the $\mathbb{T}_{1}$ is increased and the portion of the melting curves below $\mathrm{T}_{2}$ is lowered as seen in Fig. 9 - Tie molecules in semi-crystalline system should take rather extended conformations in thermodynamically equiliburium state. ${ }^{19)}$ Since such tie molecules begin to melt or relax at lower temperature due to their characteristic entropies, the semi-crystalline polymer with many tie molecules gives a lower temperature $\mathrm{T}_{1}$ than the one without tie molecules.

\section{§5. Summary}

An anisotropic structure of a specially oriented $P E$ with double texture is observed directly with EM by use of the selective etching technique by fuming nitric acid. On the $y-z$ fractured surfaces, striations with a mean period $230 \AA$ making an angle of $45 \mathrm{deg}$. with the z-axis are observed in accord with the off-meridional four-point XSAS. On the $x-z$ surfaces, rather wavy striations with a mean. period of $320 \AA$ are observed to be perpendicular to the z-axis on an average. Fibrils are estimated to be wider than 5000 A at least. 
The different roughness of the $y-z$ and $x-z$ fractured surfaces of non-treated strips indicates a preferential orientation of tie molecules to the x-axis. Results of FM observation agree well with a model of fiber with double texture proposed by Seto et al. .

Re-annealing experiments show that the FNA treatment influences the texture through change in tilting angle of chains, and this can be caused by the reduction of tie molecules. Scission of even a small fraction of tie molecules can cause appreciable lowering of the termination-temp. of melting $\mathrm{T}_{4}$, and tie molecules are also responsible on the shape of lower-temp. side of the endotherms of the fiber strips.

\section{Acknowledgements}

The auther would like to thank Professor K. Asai and Mr. H. Miyaji for their valuable discussions. Thanks are also due to Professor H. Okamoto for his continuous encouragement. 
References

1). I. L. Hay and A. Keller: J. Material Sci. I (1966) 41.

2) K. K. Kobayashi: in P. H. Geil " Polymer Single Crystals " (Interscience Publishers, New York, 1963 ) p.473.

3) A. Peterlin: J. Material Sci. 6 (1971) 490.

4) Y. Ohde, H. Miyaji and K. Asai: Japan. J. appl. Phys. 10 (1971) 171.

5) J. W. S. Hearle: J. Polymer Sci. C-20 (1967) 215.

6) N. Kasai and M. Kakudo: J. Polymer Sci. A-2,(1964) 1955.

7) K. Tanaka, T. Seto, T. Hara and Y. Tajima: Rep. Progr. Polymer Phys. Japan 7 (1964) 63.

8) T. Seto and T. Hara: Rep. Progr. Polymer Phys. Japan 9 (1966) 207.

9) T. Seto, T. Hara, Y. Tajima and H. Miyaji: in the preprints of Interm. Symposium on Macromolecular Chemistry Tokyo-Kyoto, 1966.

10) I. I. Hay and A. Keller: J. Material Sci. 2 (1967) 538.

11) J. J. Point, M. Gilliot and A. Goffin: J. Polymer Sci. C-38 (1972) 261.

12) D. M. Gezovichi and P. H. Geil; J. Material Sci. 6 (1971) 509.

13) D. M. Gezóichi and P.H. Geil: J. Material Sci. 6 (1971) 531.

14) R. P. Palmer and A. J. Cobbold: Makromol. Chem. 74 (1964) 174.

15) I. L. Hay and A. Keller: Nature 204 (1964) 862.

16) A. Peterlin and K. Sakaoku: J. appl. Phys. 38 (1967) 4152.

17) T. Kawai, K. Ebara and H. Maeda: Kolloid-Z. Z. Polymere 229 (1969) 168.

18) A. Keller and F. M. Willmouth: J. Macromol. Sci. B-6 (1972) 493.

19) H. G. Zachmann: Kolloid-Z. Z. Polymere 216-217 (1967) 180.

20) P. J. Flory: J. American Chem. Soc. 84 (1962) 2857. 
Table I Changes in the ratio $\mathrm{N}_{\mathrm{a}} / \mathrm{N}_{\mathrm{c}}$ of fiber strips with duration of the FNA treatment by re-annealing.

Strips are pre-annealed at $122^{\circ} \mathrm{C}$, then treated by FNA at $80^{\circ} \mathrm{C}$ and at last re-annealed just below respective melting points.

See the text and Fig. 8.

\begin{tabular}{c|ccc|c}
\hline $\begin{array}{c}\text { Strips treated } \\
\text { for }\end{array}$ & $\theta$ & $\varphi$ & $\alpha$ & $N_{2} / N_{c}$ \\
\hline $0 \mathrm{~h}$ & $48 \mathrm{deg}$. & $5.0 \mathrm{deg} \cdot$ & $53.0 \mathrm{deg} \cdot$ & 0.83 \\
$1 / 2 \mathrm{~h}$ & 46 & 4.5 & 50.5 & 0.80 \\
$3 / 2 \mathrm{~b}$ & 40 & 3.0 & 43.0 & 0.69 \\
$3 \mathrm{~h}$ & 29 & 1.0 & 30.0 & 0.58 \\
$6 \mathrm{~h}$ & 0 & 0 & 0 & 0.5 \\
\hline
\end{tabular}


Table II Variation of endotherms of fiber strips with heating rate. Strips are annealed at $122^{\circ} \mathrm{C}$.

\begin{tabular}{|c|c|c|c|c|c|}
\hline \multirow{2}{*}{ Strips } & \multirow{2}{*}{$\begin{array}{l}\text { Heating rate } \\
\text { per min }\end{array}$} & \multicolumn{4}{|c|}{ Characteristic Temps. } \\
\hline & & $\mathrm{T}_{1}$ & $\mathrm{~T}_{2}$ & $\mathrm{~T}_{3}$ & $\mathrm{~T}_{4}$ \\
\hline \multirow{4}{*}{$\begin{array}{l}\text { Non }= \\
\text { treated }\end{array}$} & $20{ }^{\circ} \mathrm{C}$ & $100.0^{\circ} \mathrm{C}$ & $122.5^{\circ} \mathrm{C}$ & $136.5^{\circ} \mathrm{C}$ & $153.5^{\circ} \mathrm{C}$ \\
\hline & 10 & 103.5 & 123.5 & 133.8 & 139.5 \\
\hline & 5 & 106.0 & 124.0 & 133.0 & 137.0 \\
\hline & 1 & 124.5 & 130.0 & 133.0 & 134.5 \\
\hline \multirow{4}{*}{$\begin{array}{c}\text { Preated } \\
\text { for } \\
6 \mathrm{~h}\end{array}$} & $20^{\circ} \mathrm{C}$ & $97: 0^{\circ} \mathrm{C}$ & $122.0^{\circ} \mathrm{C}$ & $131.5^{\circ} \mathrm{C}$ & $142.5^{\circ} \mathrm{C}$ \\
\hline & 10 & 100.0 & 122.5 & 130.5 & 134.0 \\
\hline & 5 & 106.0 & 123.5 & 129.5 & 132.0 \\
\hline & 1 & 124.0 & 126.5 & 129.5 & 130.5 \\
\hline
\end{tabular}


Table III. Variation of endotherm of fiber strips with duration of the treatment by FNA at $80^{\circ} \mathrm{C}$.

All the strips were pre-annealed at $128^{\circ} \mathrm{C}$ for $12 \mathrm{~h}$.

Heating rate : $5^{\circ} \mathrm{C}$ per min.

\begin{tabular}{c|cccc}
\hline $\begin{array}{c}\text { Duration } \\
\text { of }\end{array}$ & \multicolumn{4}{|c}{ Characteristic Temps. } \\
treatment & $\mathrm{T}_{1}$ & $\mathrm{~T}_{2}$ & $\mathrm{~T}_{3}$ & $\mathrm{~T}_{4}$ \\
\hline $0 \mathrm{~h}$ & $100.0^{\circ} \mathrm{C}$ & $128.0^{\circ} \mathrm{C}$ & $133.5^{\circ} \mathrm{C}$ & $140.0^{\circ} \mathrm{C}$ \\
$1 / 2 \mathrm{~h}$ & 118.0 & 127.8 & 132.5 & 135.5 \\
$2 \mathrm{~h}$ & 106.0 & 127.5 & 131.5 & 135.0 \\
$5 \mathrm{~h}$ & 105.0 & 127.0 & 131.0 & 133.5 \\
\hline
\end{tabular}


Figure captions

Fig. 1 : The axes of coordinations in the fiber strip.

Fig. 2 : X-ray scattering patterns of ( Right) small angle, and of

( Left) wide angle, taken with beams along the $x$-axis on the right one-third portion of the $\mathrm{y}-\mathrm{z}$ plane of a fiber strip. which was so fixed that the developing direction of the neck was directed upwards along the patterns.

Fig. 3 : Seto's: model of fiber with double texture, Twin-like adjacent fibrils, composed of stacks of oppositely inclined lamellar crystal-amorphous parts are arranged side by side consecutively. Hatched areas are crystalline parts and lines in the areas represent chain axes, which make an angle $\varphi$ with the z-axis. Blanked areas are amorphous parts. $\mathrm{n}_{\mathrm{L}}$; The normal of lamellae, L ; The long period, D ; The total thickness of a pair of crystalline and amorphous layers, W; The width of a fibril.

Fig. 4 : $X$-ray scattering patterns with beams along the $x$-axis, Wide angle patterns of strips ( $a$ ) non-treated, ( $b$ ) treated by FNA for $40 \mathrm{~h}$ at $80^{\circ} \mathrm{C}$. (c) Small angle pattern of the strip treated for $8 \mathrm{~h}$ at $80^{\circ} \mathrm{C}$.

Fig. 5 : Electron micrographs of fractured surfaces of non-treated strips ; ( $a$ ) the $y-z$ surface, ( $b$ ) the $x-z$ surface. 
Fig. 6 : An electron micrograph of the $x-z$ surface etched for $4 \mathrm{~h}$ after the fracture, Cr-shadowed.

Fig. 7 : An electron micrograph of the $\mathrm{y}-\mathrm{z}$ surface, treated for $8 \mathrm{~h}$ previously to the fracture.

Fig. 8 : Changes in $\mathbf{x}$-ray small angle patterns of treated and non= treated strips with re-annealing ,

Strips were pre-annealed at $122^{\circ} \mathrm{C}$, and FNA treatment was done at $80^{\circ} \mathrm{C}$.

Non-treated , ( a ) Annealed at $132.5{ }^{\circ} \mathrm{C},(\mathrm{b})$ Annealed at $132.8^{\circ} \mathrm{C}$, Treated, (c ) For $1 / 2 \mathrm{~h},(\mathrm{~d})$ For $1.5 \mathrm{~h}$, (e) For $3 \mathrm{~h}$, (if) For $6 \mathrm{~h}$, then annealed just below respective melting points.

Fig. 9 : Variations of endotherms of strips pre-annealed at $128{ }^{\circ} \mathrm{C}$ with duration of FNA treatment, Heating rate; $5^{\circ} \mathrm{C}$ per min 


$$
\text { Fig. } 1 .
$$

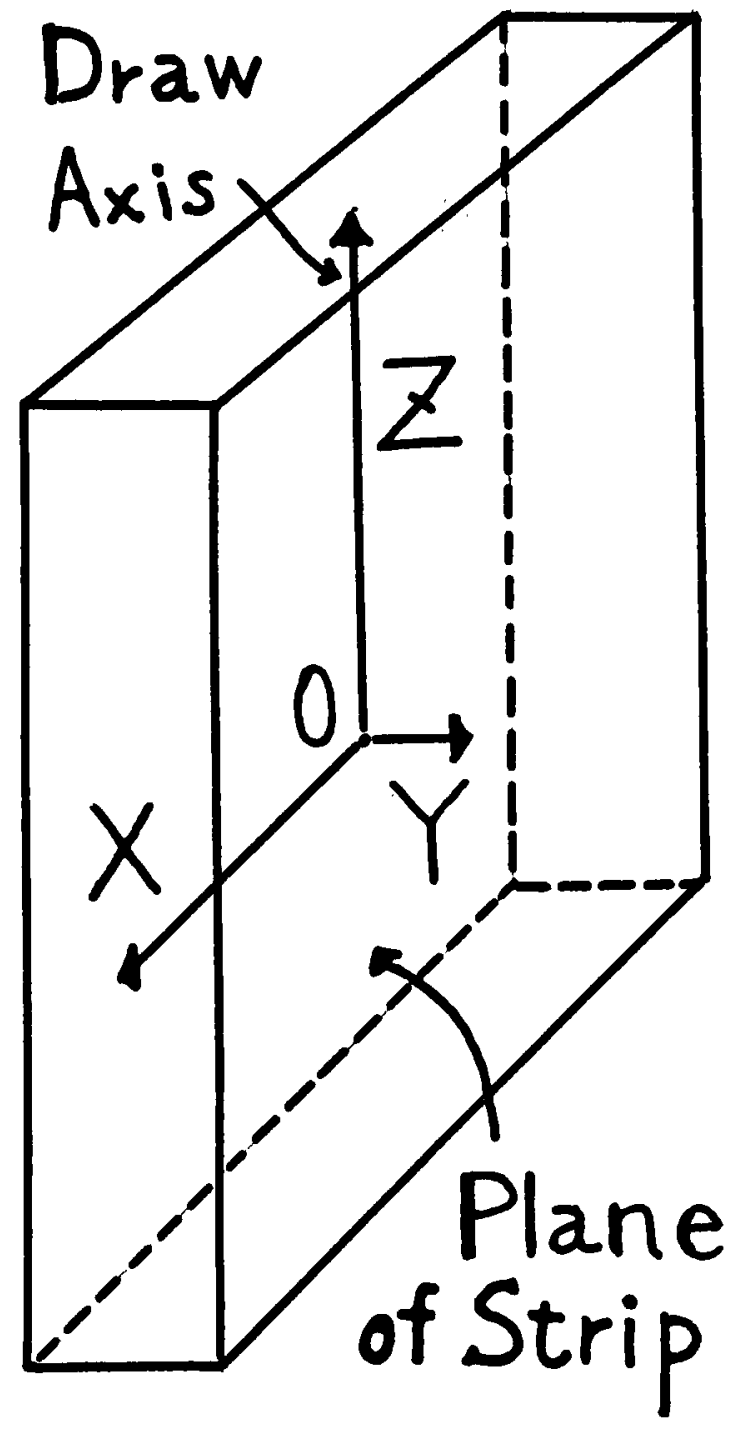


Fig. 2
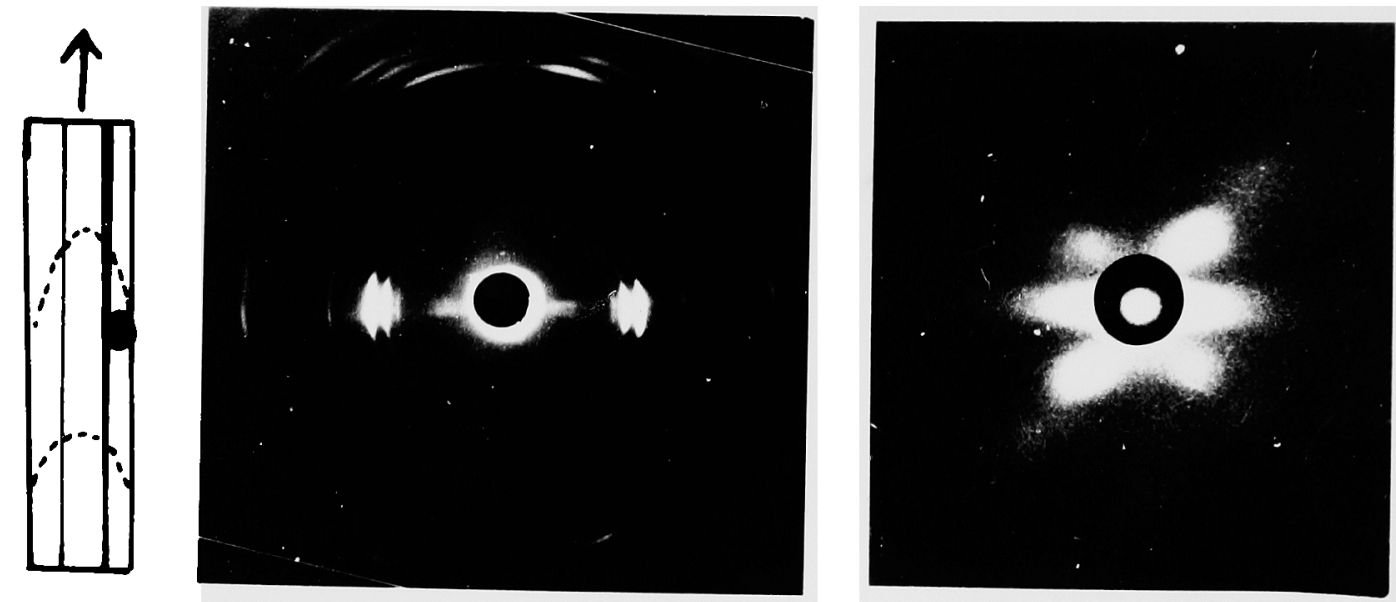

Fig.ろは次のパージ、

Fig. 4
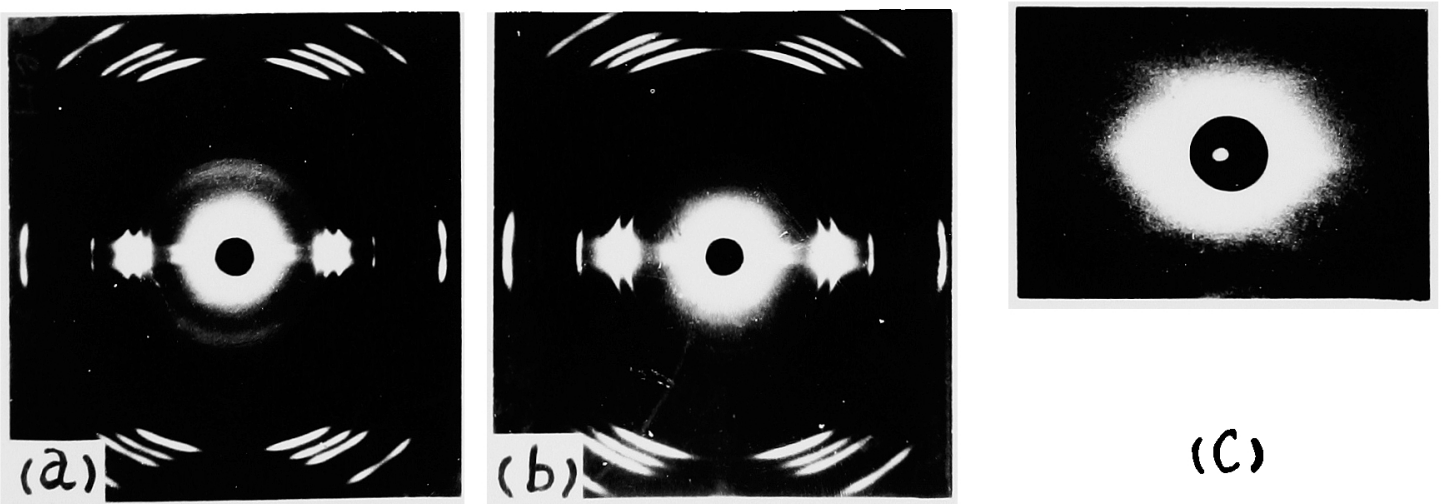
Fig. 3

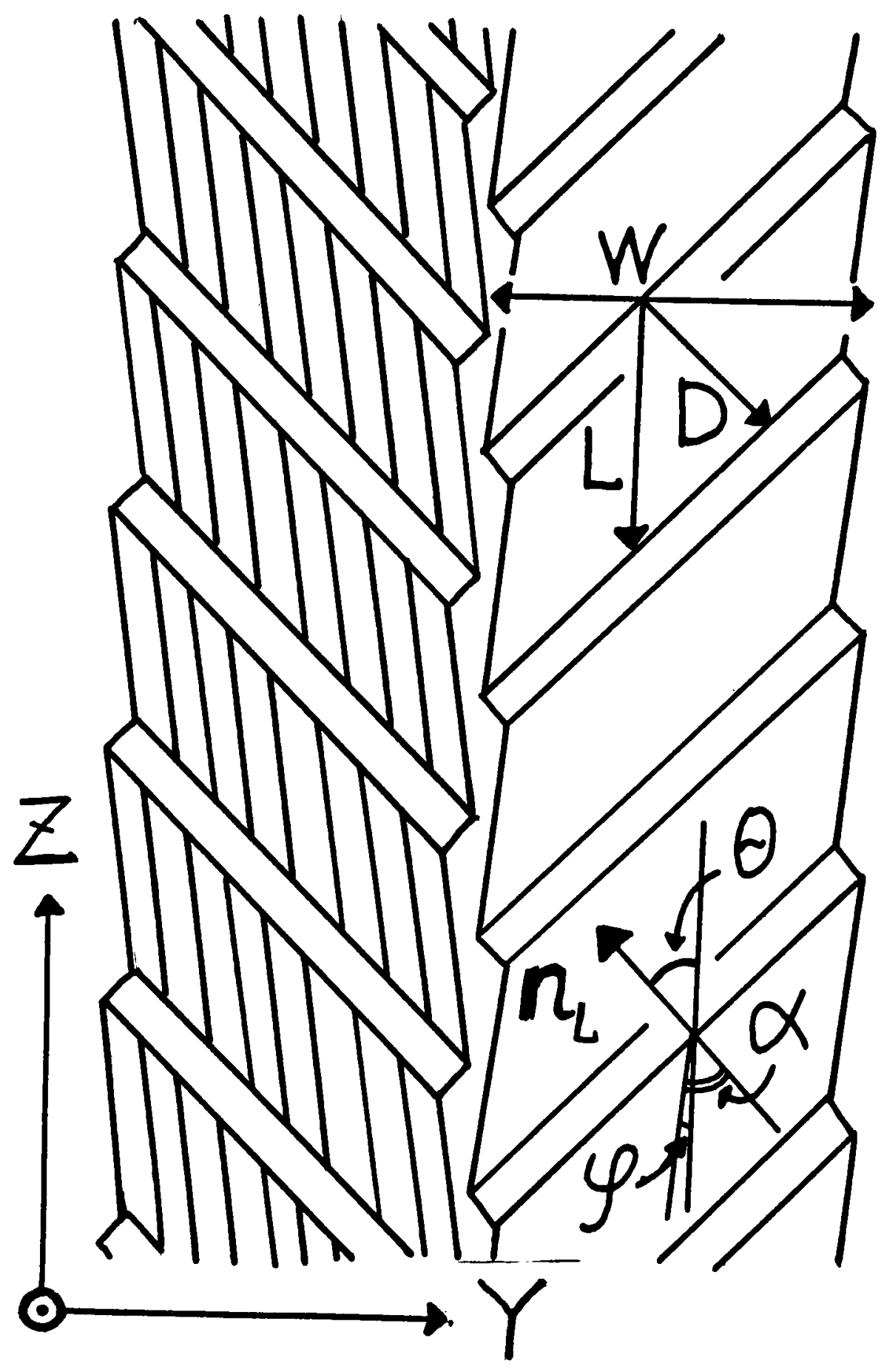




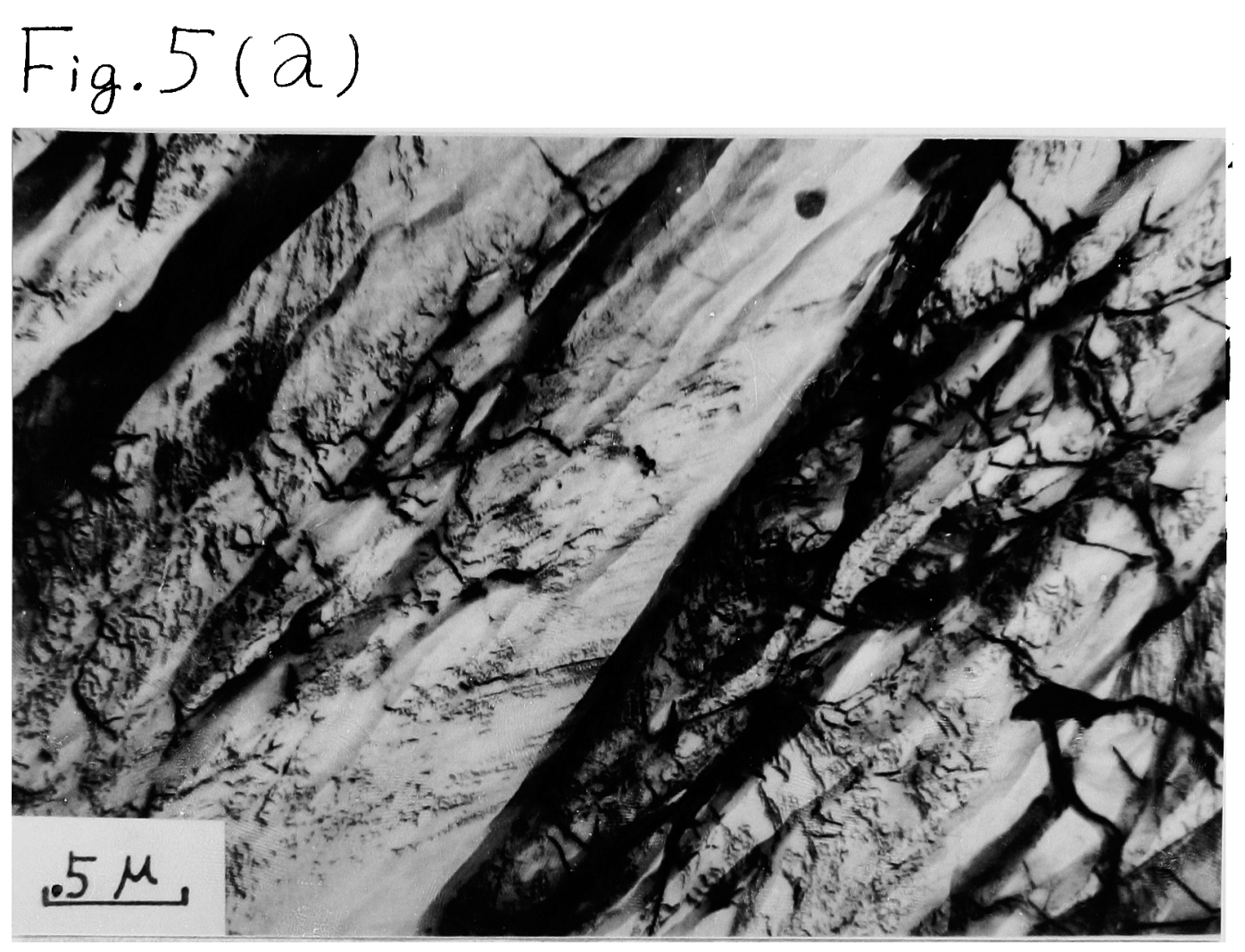

Fig. 5(b)

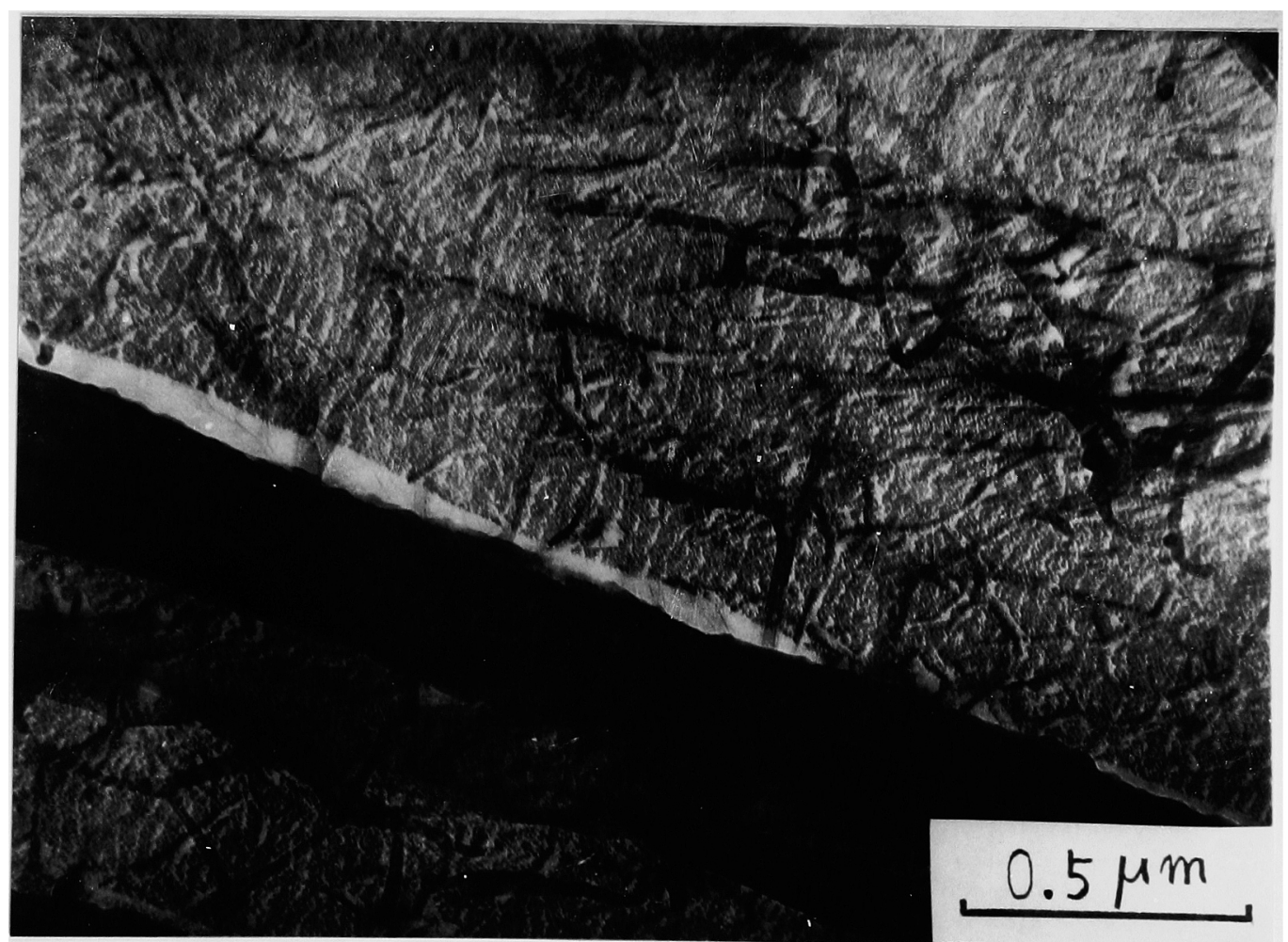


Fig. 6.

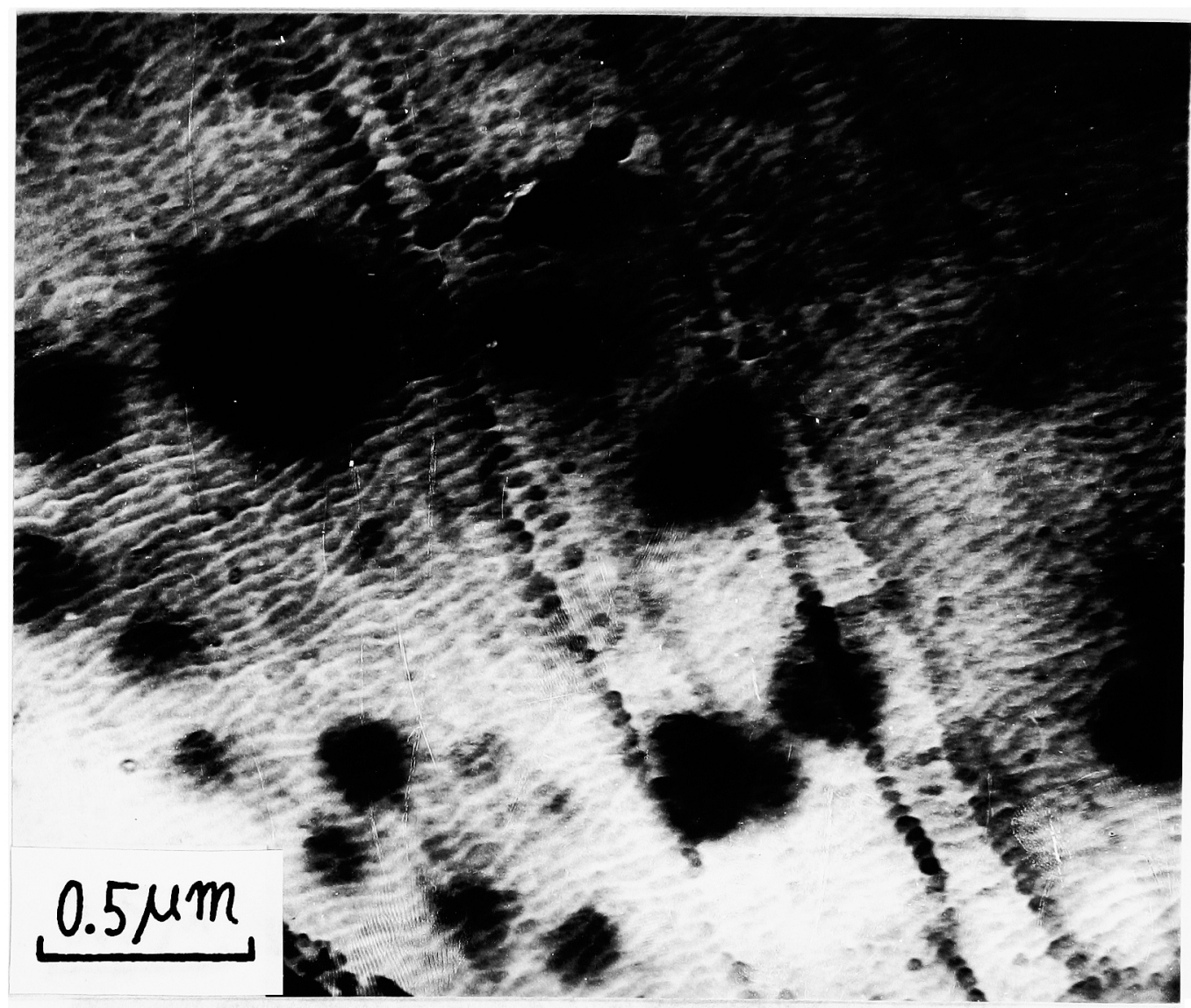


Fig. 7

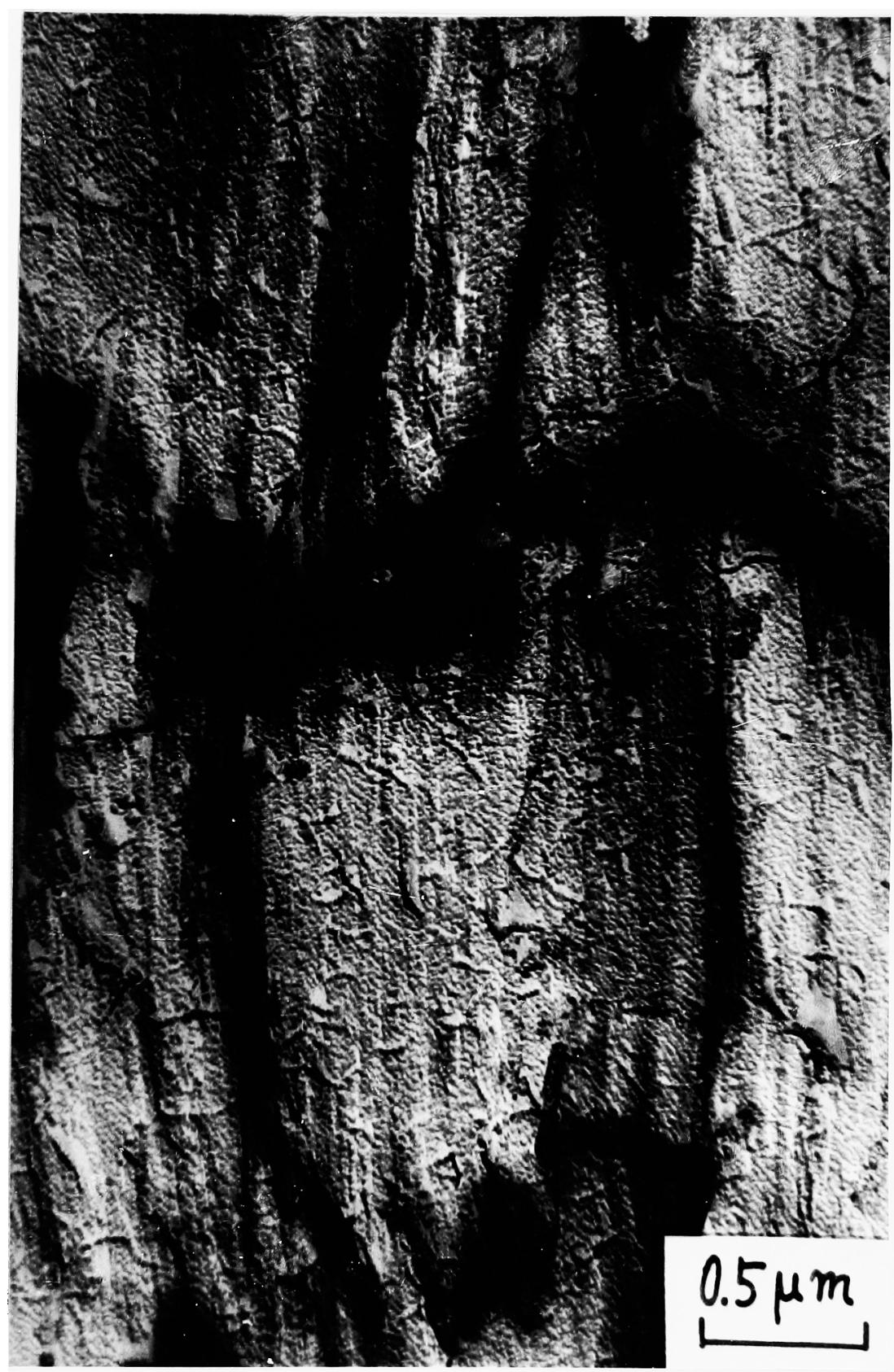


Fig. 8

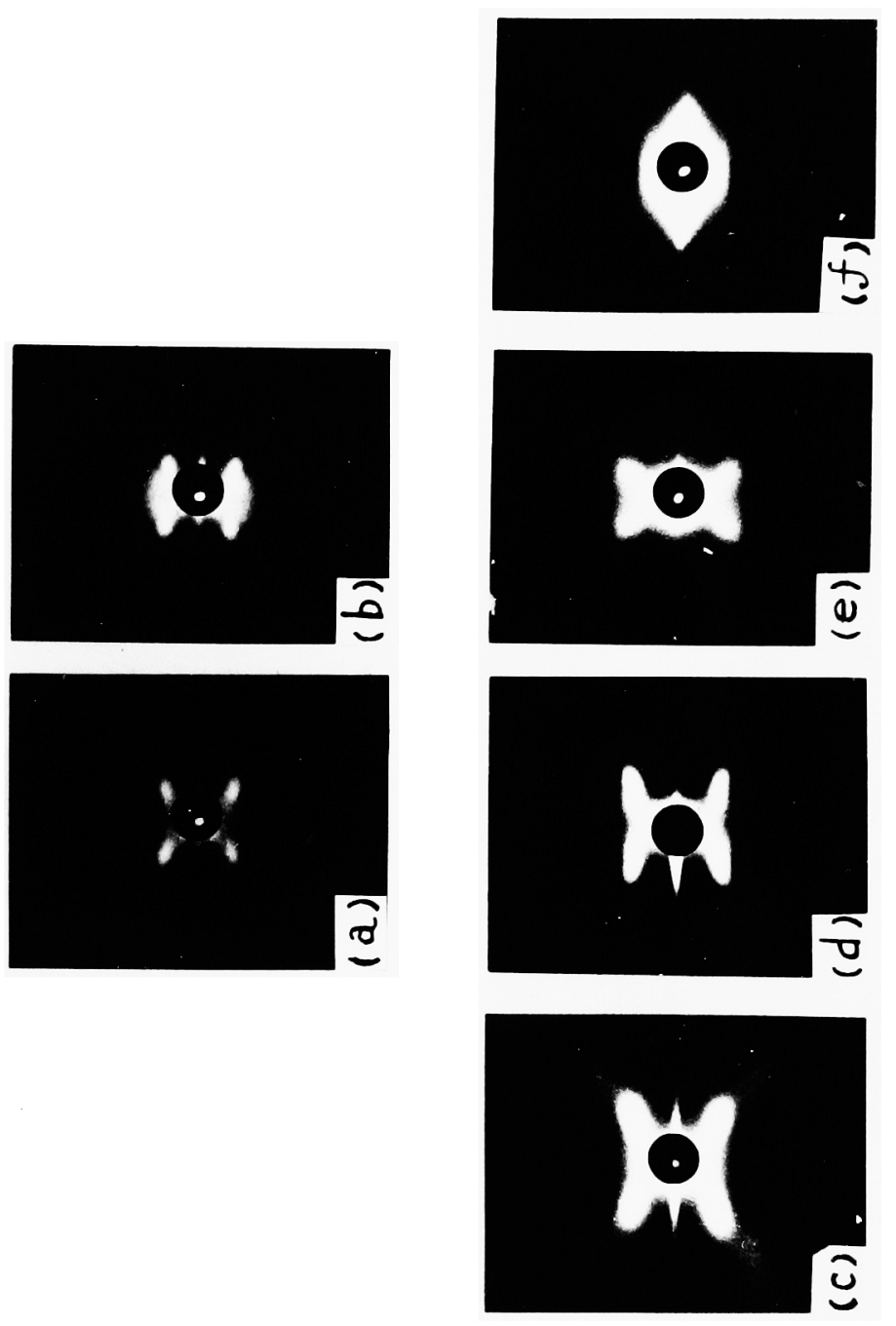


Fig. 9

28

Fig. 9.

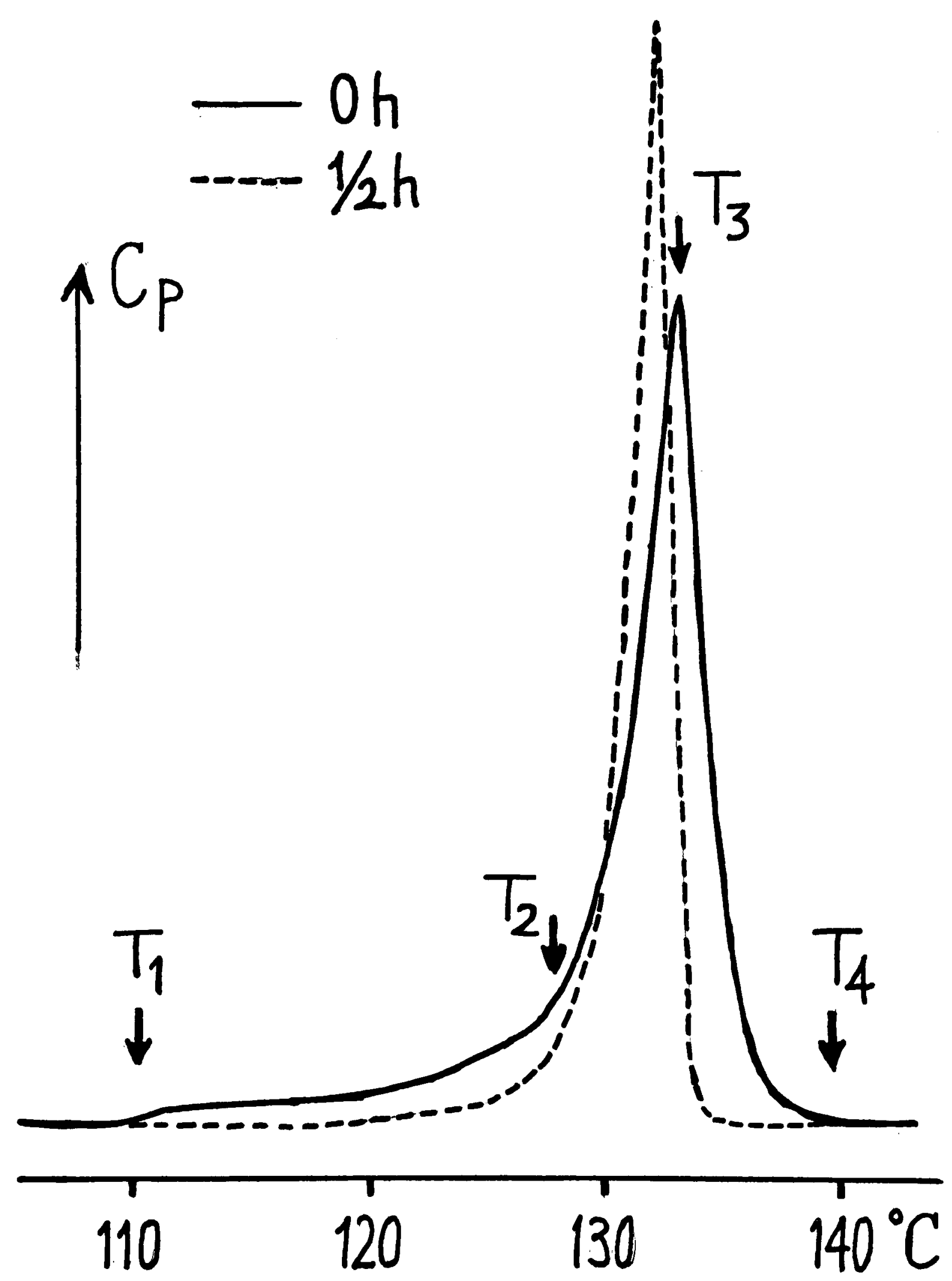

